\title{
Preventing insulin dependent diabetes mellitus: the environmental challenge
}

\author{
DIABETES EPIDEMIOLOGY RESEARCH INTERNATIONAL
}

\begin{abstract}
The epidemiology of insulin dependent diabetes mellitus was evaluated to determine the degree to which the disease results from environmental agents and therefore might be prevented. The results of research indicate that insulin dependent diabetes can be produced in animal models by environmental factors, there are major geographical variations in diabetes, certain populations have shown rapid changes in incidence over time, migrants appear to take on the risk of diabetes in their new country, and certain viruses and chemicals cause insulin dependent diabetes in humans. The results of genetic and epidemiological studies also show that at least $60 \%$ of insulin dependent diabetes world wide, and perhaps over $95 \%$, is environmentally determined and thus potentially avoidable.

It is concluded that the primary worldwide determinants of diabetes are environmental not immunogenetic and that identifying and altering the diabetogenic environmental factor(s) are likely to be more effective and less risky in preventing insulin dependent diabetes than current immunogenetic approaches.
\end{abstract}

Members of the group: Ronald E LaPorte, Janice S Dorman, and Trevor J Orchard, department of epidemiology, graduate school of public health, University of Pittsburgh; Dorothy J Becker and Allan L Drash, department of paediatrics, University of Pittsburgh; Naoko Tajima, Jikei University School of Medicine, Tokyo, Japan 105; Jean-Marie Ekoe, University of Montreal, Quebec, Canada; Jaakko Tuomilehto, National Public Health Institute, SF00280 Helsinki, Finland; Marian Rewers, Medical Academy, Poznan, Poland; Paul Zimmet, Royal Southern Memorial Hospital, Caulfield South, Victoria, Australia; Moshe Karp, Beilinson Medical Centre, Petah-Tikva, Israel; Viswanathan Mohan, Diabetes Research Centre, Royaparam, Madras 600013, India; Hong Kyu Lee, Seoul National University Hospital, Seoul 110, Korea.

Correspondence to: Dr Ronald E LaPorte, Diabetes Epidemiology Research International, Suite 502, 3600 Forbes Avenue, Pittsburgh PA 15213.

\section{Introduction}

In 1979 David Pyke wrote: "There has for many years been the widespread belief that diabetes is entirely inherited." Pyke's own research on monozygotic twins, however, proved that this concept was incorrect. As a result of the research on twins ${ }^{2-5}$ and evidence from Yoon et al and Gamble of a possible viral aetiology of insulin dependent diabetes mellitus ${ }^{67}$ the focus of research shifted in the early 1980s towards the environmental determinants of diabetes. This was short lived, however, and theory and research are again based on the assumption that insulin dependent diabetes is a genetic, albeit immunogenetic, disease. ${ }^{89}$ Though investigating the immunogenetics of diabetes is important and exciting, studies that are designed to identify the environmental agent(s) that cause diabetes should also be carried out. We believe that the challenge for the next decade is to track down the environmental agent(s) because this is likely to be the best strategy for preventing diabetes.

\section{Evidence for an environmental aetiology}

To assess the role of the environment in the aetiology of insulin dependent diabetes we adopted an approach that has been used in cancer research. There is widespread belief among cancer researchers, which is based on reports by Doll and Higgison and summarised by the World Health Organisation, ${ }^{10-12}$ that most cancer results from environmental factors and is thus preventable. Five arguments have led to these conclusions..$^{1314}$ We have evaluated these with regard to their application to diabetes.

(1) Cancer can be experimentally produced in laboratory animals by exposure to certain external agents-There is some question that in animals insulin dependent diabetes develops after exposure to certain viral agents or chemicals. ${ }^{15}$

(2) There are considerable geographical differences in the incidence of cancer-One of the most striking characteristics of insulin dependent diabetes is its enormous geographical variability. A child in Finland is 36 times more likely to develop diabetes than a child in 
Japan (fig 1). ${ }^{16}$ This international variability is greater than the 10 -fold worldwide distribution of coronary heart disease and the threefold international variation in the prevalence of cancer. ${ }^{17} 18$

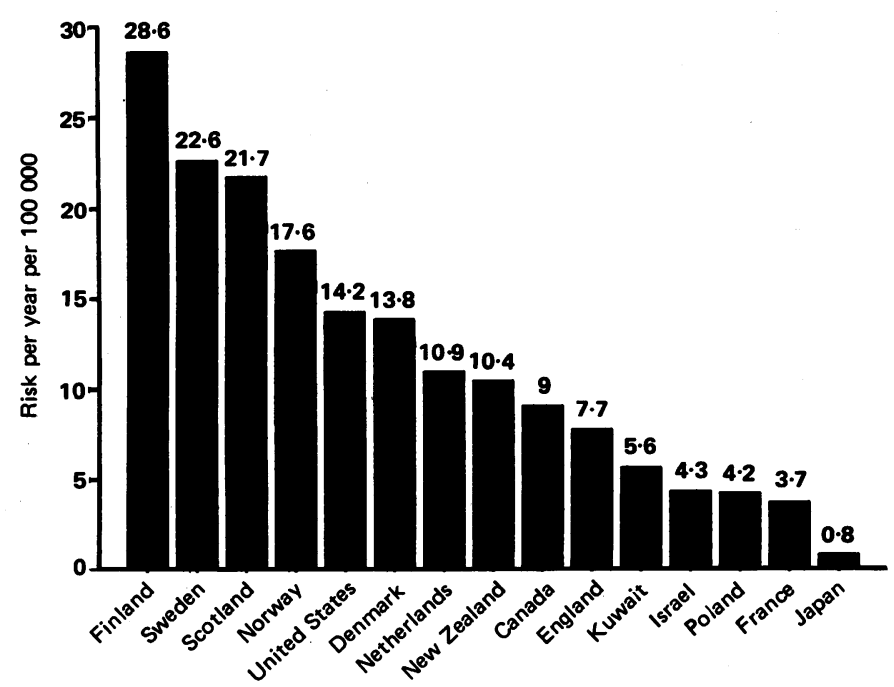

FIG 1-Incidence of insulin dependent diabetes mellitus by country.

(3) In some populations there have been rapid temporal changes in cancer incidence in less than a generation which could not result from genetic change-Data from some registries have shown marked time fluctuations in insulin dependent diabetes. ${ }^{19-24}$ In Finland the incidence rose from 13 per 100000 in the early 1950 s to 33 per 100000 in the 1980 s, a 2.5 increase in incidence in three decades. ${ }^{23}$ The most dramatic evidence is from Poland (fig 2), where in three years the incidence almost doubled. ${ }^{24}$ As far as we know such an extraordinary increase in such a short time has never been reported for any chronic disease and cannot be the result of genetic factors.

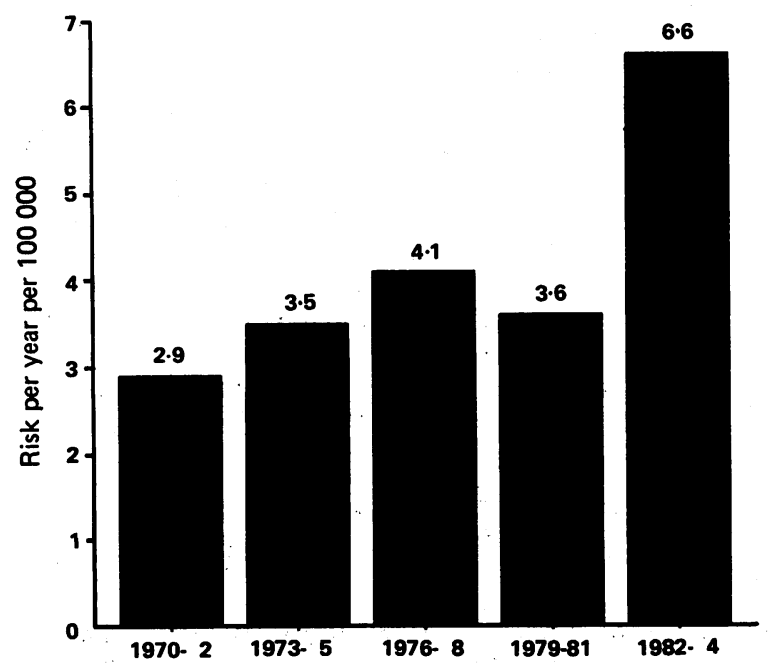

FIG 2-Incidence of insulin dependent diabetes mellitus in midwest Poland.

(4) The risk to immigrants of developing cancer rapidly begins to resemble the risk in the area they move into-Insulin dependent diabetes occurs more frequently in Japanese children who reside in Hawaii than in those in Japan, French children in Canada are twice as likely to develop diabetes as French children in France, and Jewish children in Montreal are three times more likely to develop diabetes than Jewish children in Israel (fig 3) (J Siemiatycki, personal communication) ${ }^{25-28}$ The pattern is thus similar to that in cancer studies where "low risk" populations who live in a "high risk" area take on the risk of the new area.

(5) There is strong epidemiological evidence that some environmental agents, such as smoking, alcohol, and asbestos, cause cancer in populations-There is not as much evidence on diabetes as there is on cancer, but it seems that environmental factors can cause insulin dependent diabetes in certain cases. The classic example is the child described by Yoon et al who developed diabetes and subsequently died. ${ }^{6}$ Before the onset of diabetes there was an infection with raised titres to Coxsackie virus B4, Coxsackie virus was isolated from the pancreas, and the isolated virus produced diabetes in animal models. Other findings indicate that in utero rubella infection causes diabetes later in life..$^{29}$ Moreover, inadvertent ingestion of a rat poison produces diabetes in humans. ${ }^{30}$ Thus although population data are not available (primarily because the studies have not been done), there is strong evidence that specific environmental factors produce insulin dependent diabetes.
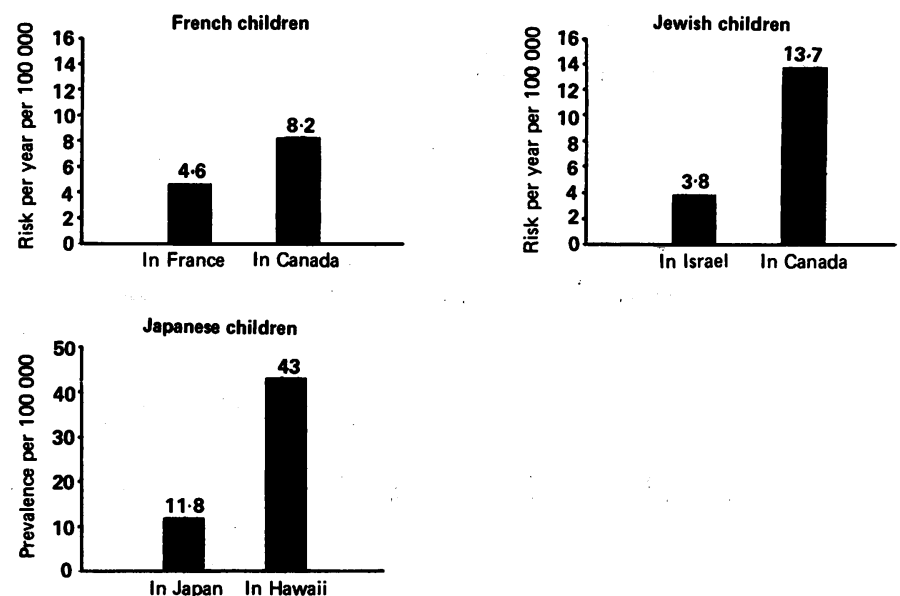

FIG 3-Prevalence of insulin dependent diabetes mellitus in children in native and adopted country.

Clearly the arguments and evidence that have attributed an environmental aetiology to cancer are directly applicable to insulin dependent diabetes mellitus. The conclusion may be reached, as with cancer, that the risk of developing insulin dependent diabetes on a population basis is primarily the result of environmental factors and is thus potentially preventable.

\section{How much is preventable?}

The results of genetic studies indicate that most genetically susceptible people do not become diabetic. For example, the results of studies of twins have shown that $50-70 \%$ of the non-diabetic monozygotic twin siblings of insulin dependent probands fail to develop diabetes. ${ }^{1.5}$ About $90 \%$ of siblings who have identical histocompatibility antigens to a diabetic child do not develop diabetes, ${ }^{31}$ and over $95 \%$ of the people who have high risk histocompatibility antigens (HLA DR3/X or HLA DR4/X) avoid diabetes. ${ }^{32}$

Epidemiological studies can also be used to estimate the degree to which insulin dependent diabetes is preventable by employing a methodology used in cancer research. Cancer researchers have argued that the lowest reported cancer rates represent "baseline" or "natural" rates. Any increase beyond these rates is ascribed to environmental factors. ${ }^{14}$ By using this method-for example with lung cancer - the ratio of the incidence rates in the lowest risk area known (Nigeria) to the highest risk country (United Kingdom) is $1: 70 .{ }^{14}$ Thus one case out of 70 is the "natural" rate, and the rest, 69 of $70(98 \%)$ of the lung cancer cases in the United Kingdom, are potentially avoidable. Using this approach, Doll and Peto argued that in the United States $70-80 \%$ of the cancers were environmental in origin and avoidable. ${ }^{18}$ 
For insulin dependent diabetes the ratio of the highest known incidence (Finland) to the lowest risk area (Japan) is 1:36. Thus, 35 of $36(97 \%)$ of the cases in Finland possibly are environmental in origin and thus preventable. Restricting the comparison to white populations shows that the ratio of risk of children in low risk areas such as Poland or France to high risk Finland is 1:7. ${ }^{232426}$ Thus at least $85 \%$ (6 of 7 ) of the cases of diabetes in whites in Finland are potentially avoidable. It may be argued that these geographical comparisons provide only weak evidence because the differences in incidence between two countries may still be genetically determined even if the groups are of the same race. The primary geographical differences in the incidence of diabetes, however, do not appear to be associated with the prevalence of high risk HLA antigens-that is, in countries that have a low frequency of the HLA antigens associated with diabetes the populations do not necessarily have a low risk for insulin dependent diabetes. ${ }^{163}$ Moreover, the genetic issue in epidemiological studies may be circumvented by examining populations that have the same gene pool-for example, the same population over time or migrant populations. The $2 \cdot 5$-fold increase in the incidence of diabetes in Finland in $\mathbf{3 0}$ years indicates that at least $60 \%$ of the recent cases in Finland were environmentally determined. ${ }^{23}$ Similarly, the threefold increased risk among Jewish people in Montreal compared to that in Israeli Jews indicates that $66 \%$ of cases among the Canadian Jewish population is avoidable. ${ }^{28}$

Overall the genetic and epidemiological publications consistently show that at least $60 \%$ and perhaps over $95 \%$ of diabetes in children would be prevented if the agents could be identified and the prevalence of these factors reduced.

\section{Conclusion}

This review is not intended to negate the importance of the immunogenetic research in diabetes but to point out that most genetically susceptible people do not become diabetic. Thus the risk of diabetes across populations is primarily the result of some form of exposure.

It is important also to consider the immunogenetic and environmental approaches with regard to the prevention of insulin dependent diabetes. Suppose the specific "diabetogenic" gene were found where $100 \%$ of cases and no non-diabetics have the genetic marker. Would this rapidly lead to the prevention of diabetes? Probably not. We know of no disease in which a genetic marker has been identified and the disease incidence has been rapidly reduced. Alternatively, suppose the specific immunological defect is identified. Here we are confronted with the dilemma of how to rectify the problem. Even if it was possible to prevent diabetes in children by tampering with the immune system the benefits of immunological "prevention" may be outweighed by risks of other conditions, such as infection, cancer, or drug toxicity.

In contrast, identifying the environmental determinants for insulin dependent diabetes could lead to an effective and safer "preventive" approach, as, for example, in tuberculosis and malaria, declining smoking rates and a reduction in lung cancer, and the identification of carcinogenic as well as teratogenic drugs. Reducing the prevalence of the environmental factors that produce the 36-fold geographical variation world wide and the epidemic of diabetes in Poland would be effective in reducing the incidence of disease, and it would be less expensive with less risk attached than immunogenetic "cures."

We conclude as Pyke did in 1979: “. . . non-genetic factors exist which operate in genetically predisposed individuals to produce [insulin dependent diabetes mellitus] but we do not know what these factors are".' The evidence indicates that most of the diabetes that develops world wide can be prevented-not through altering the immune system but through reducing the prevalence of the environmental risk factors.

Research in the Department of Epidemis:logy, Graduate School of Public Health, University of Pittsburgh, was supported by NIH grant R01 AM35905 and R01 DK24021. Research in the National Public Health Institute, Helsinki, Finland was supported by NIH grant R01 DK37957 and by the Sigrid Juselius Foundation. The authors thank Dr Jack Siemiatycki for helpful comments.

\section{References}

1 Pyke DA. Diabetes: the genetic connections. Diabetologia 1979;17:333-43.

2 Pyke DA. Concordance of diabetes in MZ twins. In: Mimura G, Baba S, Goto Y, Kobberling J, eds. Clinico-genetic genesis of diabetes mellitus. Amsterdam: Excerpta Medica, 1982:309-13. (International congress series 597 .)

3 Tattersall RB, Pyke DA. Diabetes in identical twins. Lancet 1972;ii:1120-5.

4 Millward BA, Alviggi L, Hoskins PJ, et al. Immune changes associated with insulin dependent diabetes may remit without causing the disease: a study in identical twins. $\mathrm{Br} M e d f$ 1986;292:793-6.

5 Barnett AH, Eff C, Leslie RDG, Pyke DA. Diabetes in identical twins. Diabetologia 1981;20: 87-93.

6 Yoon JW, Autin M, Onodera T, Notkins AL. Virus induced diabetes mellitus: isolation of a virus from the pancreas of a child with diabetic ketoacidosis. N Engl f Med 1979;300:1173-9.

7 Gamble DR. The epidemiology of insulin dependent diabetes mellitus with particular reference to the relationship of virus infection to etiology. Epidemiol Rev 1980;2:49-70.

8 Eisenbarth GS. Type I diabetes mellitus: a chronic autoimmune disease. $N$ Engl $7 \mathrm{Med}$ 1986;314:1360-8.

9 Botazzo GF, Pujol-Borrel R, Gale E. Etiology of diabetes: the role of autoimmune mechanisms. In: Alberti KGMM, Krall LP, eds. Diabetes annual/1. Amsterdam: Elsevier Science, 1985: 16-52.

10 Doll R. Prevention of cancer-pointers from epidemiology. London: Nuffield Provincial Hospitals Trust, 1967.

11 Higgison J. Present trends in cancer epidemiology. In: Morgan JF, ed. Proceedings of the eighth Canadian cancer conference. Toronto: Pergamon Press, 1969:40-75.

12 World Health Organisation. Prevention of cancer. WHO Tech Rep Ser 276, 1964.

13 Schneiderman MA. Eighty percent of cancer is related to the environment. Laryngoscope 1978;88:559-74.

14 Wynder EL, Gori GB. Contribution of the environment to cancer incidence: an epidemiologic exercise. Fournal of the National Cancer Institute 1977;58:825-32.

15 Renold AE. Possible animal models for diabetes mellitus: syndromes involving toxic or immune etiology. In: Alberti KGMM, Krall LP, eds. Diabetes Annual/1. Amsterdam: Elsevier Science, 1985:492-508.

16 LaPorte RE, Tajima N, Akerblom HK, et al. Geographic differences in the risk of insulindependent diabetes mellitus: the importance of registries. Diabetes Care 1985;8(suppl 1) 101-7.

17 Keys A. Coronary heart disease in seven countries. New York: American Heart Association, 1970 (American Heart Association Monograph No 29.)

18 Doll RS, Peto R. The causes of cancer: quantitative estimates of avoidable risks of cancer in the United States today. Oxford: Oxford University Press, 1981:1205-7.

19 North AF, Gorwitz K, Sultz HA. A secular increase in the incidence of juvenile diabetes mellitus. T Pediatr 1977;91:706-10.

20 Stewart-Brown S, Haslum M, Butler N. Evidence for increasing prevalence of diabetes mellitus in childhood. Br Med f 1983;286:1855-7.

21 Dahlquist G, Blom L, Holmgren G, et al. The epidemiology of diabetes in Swedish children 0-14 years-a six-year prospective study. Diabetologia 1985;28:802-8.

22 Patterson CC, Thorogood M, Smith PG, Heasman MA, Clarke JA, Mann JI. Epidemiology of type 1 (insulin-dependent) diabetes in Scotland 1968-1976: evidence of an increasing incidence. Diabetologia 1983;24:238-43.

23 Reunanen A, Akerblom H. A national drug register as a data source in the study of the epidemiology of IDDM in children in Finland. In: Serrano-Rios M, Lefebvre PJ, eds. Diabetes. Amsterdam: Elsevier Science, 1985.

24 Rewers M, LaPorte RE, Walczak M, Dmochowski K, Bogaczynska E. An apparent "epidemic" of youth onset insulin dependent diabetes mellitus in midwestern Poland. Diabetes 1987;36: of youth $106-13$.

25 Mimura G. Present status and future view of the genetic study of diabetes mellitus. In: Mimura G, Baba S, Goto Y, Kobberling J eds. Clinico-genetic genesis of diabetes mellitus. Amsterdam: Excerpta Medica, 1982:xiii-xxviii. (International congress series 597.)

26 Hocus M, Fabry J, Siemiatycki J, Francois R. Diabete insulino-dependant juvenile. Etude descriptive dans le department du Rhone. Rev Epidemiol Sante Publique. 1984;32:107-12.

27 Colle E, Siemiatycki J, West R, et al. Incidence of juvenile onset diabetes in Montreal: demonstration of ethnic differences and socioeconomic class differences. $\mathcal{J}$ Chronic $D$ is 1981;34:611-6.

28 Laron Z, Karp M, Modan $M$. The incidence of insulin dependent diabetes mellitus in Israeli children and adolescents 0-20 years of age: a retrospective study, 1975-80. Diabetes Care $1985 ; 8: 24-8$.

29 Muser MA, Forrest JM, Bransby RD. Rubella infection and diabetes mellitus. Lancet 1978;i: 57-60.

30 Prosser PR, Karam JH. Diabetes mellitus following rodenticide ingestion in man. fAMA 1978;239:1148-50.

31 Cavender DE, Wagener DK, Rabin BS, et al. The Pittsburgh insulin-dependent diabetes mellitus (IDDM) study. HLA antigens and haplotypes as risk factors for the development of IDDM in IDDM patients and their siblings. $f$ Chron Dis 1984;37:555-69.

32 Tiwari JL, Terasaki PI. HLA and disease association. New York: Springer, 1985:185-210.

33 Tajima N, LaPorte RE, Hibi I, Kitagawa T, Fujita $\mathrm{H}$, Drash AL. A comparison of the epidemiology of youth onset insulin-dependent diabetes between Japan and the United States (Allegheny County, Pennsylvania). Diabetes Care 1985;8(suppl 1):17-23.

(Accepted 29 April 1987) 